phần của chễ đô điều trị ức chế miễn dịch. Trong số hai thuốc trên thì tacrolimus được cho rằng có nguy cơ gây đái tháo đường nhiều hơn, khoảng 50\%. Không giống như steroid, các thuốc này khả năng gây tăng đường huyết không phụ thuộc vào liều, mặc dù điều này vẫn còn tranh cãi. Tacrolimus là thuốc ức chế calcineurin đang ngày càng được ưu tiên sử dụng tại hầu hết các trung tâm ghép do ưu điểm hiệu quả và an toàn, mặc dù có nguy cơ gây đái tháo đường. Sự thiếu hụt calcinerin dẩn đến giảm sản xuất insuline. CNI ức chế sự hấp thụ glucose ở tế bào do giảm số lượng thụ thể vận chuyển glucose loại 4 (GLUT-4) trên bề mặt tế bào mõ. GLUT-4 là một protein điều tiết insuline có mặt chủ yếu ở mô mỡ và cơ, giúp vận chuyển glucose vào tế bào chất của tế bào. Do đó, việc giảm GLUT-4 dễn đến tăng đường huyểt. Tacrolimus còn giảm hoạt động của enzyme glucokinase tại tiểu đảo tụy, vì thế ức chế việc giải phóng insuline nhờ xúc tác từ glucose. Ngoài hai cơ chế làm ức chế giải phóng insuline và tăng kháng insuline ở mô kể trên, sử dụng CNI được chỉ ra làm phù nề tế bào chất và không bào, biến đổi insuline, ngoài ra CNI còn được cho là ức chế biểu hiện gene mã hóa insuline.

Cũng trong nghiên của này của chúng tôi khi xét mối liên quan của các thuốc kể trên với sự phát triển NODAT, kết quả cho thây hầu hết đối tượng sử dụng các thuốc kể trên không cho sự khác biệt giữa phát triển NODAT và không NODAT; chỉ ở đối tượng sử dụng corticoid tỉ lệ bênh nhân bi NODAT là $12,47 \%$ trong khi không NODAT chiếm $87,53 \%$ sự khác biệt có ý nghĩa thống kê với $p<0,001$. Tỉ lệ NODAT cao ở nhóm không dùng corticoid ở thời điểm hiện tại cũng là do trong nhóm đã được chẩn đoán NODAT trước đây đã được dừng corticoid để tránh tăng đường huyết khó kiểm soát. Kết quả của chúng tôi không giống như những báo cáo đã trình bày ở trên, có lẽ do thời điểm khảo sát, hầu hết các đối tượng đã được can thiệp điều trị tình trạng đái tháo đường vì thế có thể ảnh hưởng nhiều đến việc đối chiếu so sánh.

\section{KẾT LUÂ̂N}

Điều chỉnh chế độ sử dụng thuốc ức chế miễn dịch đặc biệt là corticoid có thể làm thay đổi nguy cơ phát triển đái tháo đường sau ghép thận.

\section{TÀI LIẸU THAM KHẢO}

1. Luan, F.L., D.E. Steffick, and A.O. Ojo, Newonset diabetes mellitus in kidney transplant recipients discharged on steroid-free immunosuppression. Transplantation, 2011. 91(3): p. 334-41.

2. Rodrigo, E., et al., New-onset diabetes after kidney transplantation: risk factors. J Am Soc Nephrol, 2006. 17(12 Suppl 3): p. S291-5.

3. Kamar, N., et al., Diabetes mellitus after kidney transplantation: a French multicentre observational study. Nephrol Dial Transplant, 2007. 22(7): p. 1986-93.

4. Vincenti, F., et al., Results of an international, randomized trial comparing glucose metabolism disorders and outcome with cyclosporine versus tacrolimus. Am J Transplant, 2007. 7(6): p. 1506-14.

5. Davidson, J., et al., New-onset diabetes after transplantation: 2003 International consensus guidelines. Proceedings of an international expert panel meeting. Barcelona, Spain, 19 February 2003. Transplantation, 2003. 75(10 Suppl): p. Ss3-24.

\title{
NGHIÊN CỨU HÌNH ẢNH VÕNG MAC VÙNG HOÀNG ĐIỂM BẰNG OCT SAU PHẪU THUÂ̂T BONG VÕ்NG MẠC QUA HOÀNG ĐIỂM
}

\section{TÓM TẮT}

Mục tiêu: Ngiên cứu nhằm Mô tả hình ảnh võng mạc vùng hoàng điểm bằng $\mathrm{OCT}$ trên bệnh nhân bong võng mạc qua hoàng điểm đã được điều trị và tìm hiểu một số yếu tố liên quan với tình trang võ̉ng mac vùng hoàng điểm. Thiết kế nghiên cứu: nghiên cứu

\footnotetext{
${ }^{1}$ Đai hoc Y Hà Nôi

${ }^{2}$ Bềnh viện mắt Trung Uơng

Chịu trách nhiệm chính: Nguyễn Thị Phương Thảo Email: nguyenthaovnio@gmail.com

Ngày nhận bài: 6.01.2021

Ngày phản biên khoa hoc: 4.3.2021

Ngày duyệt bài: 15.3.2021
}

Nguyễn Thị Phương Thảo ${ }^{1}$, Cung Hồng Sơn ${ }^{2}$ mô tả tiến cứu theo dõi dọc. Đối tượng và phương pháp: 31 mắt có $B V M$ có bao gồm hoàng điểm, có vết rách nguyên phát được điêu trị ở Bệnh Viện Mắt Trung Ương từ tháng 1 - 2014 đến tháng $7-2014$. PT thành công bằng CDK hoăc đai độn CM. Thời gian nhìn mờ $\leq 30$ ngày. Lập hồ sơ đánh giá thời gian xuất hiện triệu chứng, phương pháp phẫu thuật... Tiến hành khám bênh nhân đo thỉ lực, làm OCT của bênh nhân trên các thời điểm khám sau PT 6 tuân và 3 tháng để đánh giá tình trang VM vùng hoàng điểm bao gồm thay đổi hình thái và vi cấu trúc VM và tìm hiểu 1 số yếu tố liên quan đến những bất thường này. Kết quả: bất thường hình thái vùng hoàng điểm trên OCT: $12 / 31$ mắt $(38,7 \%)$ trong đó dịch dưới võng mạc(DDVM) hay gặp nhất $10 / 31$ mắt $(32,3 \%)$ sau 6 
tuân.Sau 3 tháng có $9 / 31$ mắt $(29,1 \%)$ còn DDVM. Thị lực của nhóm có DDVM thấp hớn có ý nghĩa thống kề với nhóm không có. Không có mắt nào còn DDVM trên OCT có TL > 20/50 trong khi đó sau 6 tuần có $9 / 21$ mắt $(42,9 \%)$ và $12 / 22$ mắt( $54,5 \%) 3$ tháng sau phẫu thuật có $T L>20 / 50$. Những bệnh nhân có bong VM qua hoàng điểm với thời gian nhỏ hơn hoặc bằng 3 ngày ít có bất thường hình thái trên OCT hớn so với những bệnh nhân mố muộn hơn $(p<0,05)$. Kết luận: Mắc dù sau điều trị bong VM qua hoàng điểm thành công làm áp lại VM trên lâm sàng nhưng trên hình ảnh OCT phát hiện nhiều bất thường vùng hoàng điểm. Những bất thường này có giá trị trong giải thích cũng như tiên lượng khả năng hồi phục TL của bệnh nhân. Việc phẫu thuật sớm sẽ hạn chế những bất thường hình thái trên OCT như tình trang DDVM.

Tư khóa: BVM qua hoàng điểm, OCT

\section{SUMMARY}

\section{EVALUATION OF MACULAR BY OCT AFTER} MACULAR OFF RETINAL DETACHMENT SURGERY

Purpose: To evaluate foveal anatomical abnormalities in OCT after the successful repair of rheqmatogenous retinal detachments (RRD) and analyze some correlated factors. Design: Prospective observational study. Methods: 31 eyes with macular off RRD have anatomically successful reattachment after the first surgery in Vietnam national institute of ophthalmology from January 2014 to July 2014 and duration of decrease visual acuity sign is (VA) $\leq 30$ days. Complete medical and ophthalmic histories, $B C V A$, duration of symptoms, number of breaks, extent of the retinal detachment (RD), and type of surgery were recorded. All patients underwent clinical examination, optical coherence tomography (OCT) scan of the macula 6weeks, 3 months after surqery. OCT images were analyzed to find out foveal anatomical abnormalities. We also find some factors have relative correlated with these abnormalities. Results: Foveal anatomic abnormalities were detected in $12 / 31$ eyes $(38.7 \%)$, persistence of subretinal fluid (PSF) was the most frequent with $10 / 31$ eves $(32.3 \%)$ and $9 / 31(29.1 \%)$ after 6 weeks and 3 months. BCVA of PSF group was lower than the remain group $(p<0.05)$. All PSF eyes hadn't BCVA $>20 / 50$ while $9 / 21$ eyes $(42.9 \%)$ after 6 weeks and $12 / 22$ eyes $(54.5 \%)$ after 3 months had BCVA $>20 / 50$. Mean postoperative BCVA (20/145 $\pm 20 / 132$ versus 20/53 $\pm 20 / 32$ after 6 weeks; after 3 months $20 / 135 \pm 20 / 132$ versus $20 / 46 \pm 20 / 35)(p<0.05)$ was significantly different among these subgroups. Patients treated after 3 days from the first decrease of VA had more abnormalities than the other $(p<0.05)$. Conclusion: After anatomically successful RRD repair, OCT is shown as a useful noninvasive diaqnostic to detect foveal anatomical abnormalities. These abnormalities have hiqh value in explain and proqnosis BCVA of patient. Early treatment can be helpful in decrease these abnormalities.

Keyword: macular off retinal detachment, OCT

\section{I. ĐĂT VẤN ĐỀ}

Tỷ lệ thành công về mặt giải phẫu của phẫu thuật bong võng mạc (BVM) với võng mạc áp sau phẫu thuật là hơn $80 \%$ sau 1 lần phẫu thuật. ${ }^{1,2}$ Tuy nhiên thị lực sau phẫu thuật của bệnh nhân có thể không được hồi phục hoàn toàn, nhất là những trường hợp bong võ̃ng mạc qua hoàng điểm. Điều này có thể được lý giải bởi sự thay đổi cấu trúc của vùng hoàng điểm mà người khám không thể phát hiện qua soi đáy mắt trên lâm sàng. ${ }^{3}$

Với sự phát triển của các phương pháp thăm dò chẩn đoán hình ảnh mới đặc biệt là chụp cắt lớp võng mạc cấu kết (OCT - Optical Coherence Tomography) có thể phát hiện những bất thường dưới lâm sàng bao gồm sự dày lên của võng mạc vùng hoàng điểm, tồn lưu dịch dưới võng mạc và nang võng mạc được cho là có mối tương quan với sự phục hồi thị lực kém sau phẫu thuật. ${ }^{3}$ Chúng tôi tiến hành đề tài "Nghiên cứu hình ảnh võng mạc vùng hoàng điểm bằng OCT sau phẫu thuật bong võng mạc qua hoàng điểm" nhằm muc tiêu:

1. Mồ tả hình ảnh võng mạc vưng hoàng điểm bằng OCT trên bệnh nhân bong võng mạc qua hoàng điểm đã được điều trị.

2. Tìm hiểu một số yếu tố liên quan, với tinh trạng võng mạc vùng hoàng điểm.

\section{II. ĐỐI TƯợNG VÀ PHƯƠNG PHÁP NGHIÊN CứU}

Đối tượng nghiên cứu. Những bệnh nhân được chẩn đoán bong võng mạc có bao gồm hoàng điểm, có vết rách nguyên phát được điều trị ở Bệnh Viện Mắt Trung Ương từ tháng 1 2014 đến tháng 7 - 2014. Được phẫu thuật bong võng mạc nguyên phát qua hoàng điểm bằng phương pháp cắt dịch kính (CDK) bơm khí nội nhãn hay đai, độn củng mạc đơn thuần thành công.

Phương pháp nghiên cứu: Nghiên cứu tiến cứu theo dõi dọc.

Mẫu nghiên cứu: 31mắt trên 31 bệnh nhân bong võng mạc qua hoàng điểm.

Tiêu chuẩn lựa chọn. Bệnh nhân được phẫu thuật bong võng mạc nguyên phát qua hoàng điểm bằng phương pháp cắt dịch kính (CDK) bơm khí hay đai, độn củng mạc đớn thuần thành công. Có thời gian giảm thị lực rõ trong phạm vi 30 ngày kể từ ngày đầu tiên của bong võng mạc đến ngày vào viện.

Tiêu chuẩn loại trừ. Phẫu thuật có bơm dầu nội nhãn hay phải phẫu thuật lại. BVM thứ phát do các nguyên nhân khác như chấn thương, BVM co kéo. Bệnh nhân có tiền sử các bệnh mắt khác như viêm màng bồ đào, glôcôm hay tắc mạch võng mạc cũ. Tăng sinh dịch kính võng 
mạc từ mức độ $\mathrm{C}$ trở lên, xuất huyết dịch kính. Bệnh dịch kính võng mạc khác như bệnh thoái hóa hoàng điểm tuổi già hay bệnh võng mạc đái tháo đường.

Các bước tiến hành nghiên cứu. Bệnh nhân được khám lâm sàng trước phẫu thuật và khám lại vào các thời điểm 1 tuần, 6 tuần và 3 tháng sau phẫu thuật để: Đánh giá thị lực, nhãn áp, Đánh giá tình trạng VM áp trên lâm sàngChụp cắt lớp $\mathrm{VM}$ vào thời điểm sau 6 tuần và sau 3 tháng bằng máy Cirrus $\mathrm{HD} O C T$, hình ảnh thu được chỉ được chấp nhân với mức tín hiêu từ $5 / 10$ trở lên. Số liệu thu thập được xử lý bằng phần mềm SPSS 16.0.

III. KẾT QUẢ NGHIÊN CỨU VÀ BÀN LUÂ̂N

3.1 Những bất thường về hình thái trên $O C T$

Bảng 1. Những bât thường về hình thái trên OCT sau phẩu thuật

\begin{tabular}{|c|c|c|}
\hline OCT & $\begin{array}{c}\text { Sau } \mathbf{6} \\
\text { tuần } \\
\mathbf{n}(\%)\end{array}$ & $\begin{array}{c}\text { Sau 3 } \\
\text { tháng } \\
\mathbf{n}(\mathbf{\%})\end{array}$ \\
\hline Khồng có bất thường & $19(61,3 \%)$ & $19(61,3 \%)$ \\
\hline $\begin{array}{c}\text { Dịch dưới võng mạc tập } \\
\text { trung }\end{array}$ & $6(19,4 \%)$ & $6(19,4 \%)$ \\
\hline DDVM nhiếu nang & $4(12,9 \%)$ & $3(9,7 \%)$ \\
\hline Màng trước võng mạc & $1(3,2 \%)$ & $2(6,5 \%)$ \\
\hline $\begin{array}{c}\text { Hội chứng co kéo dịch } \\
\text { kính hoàng điểm }\end{array}$ & $1(3,2 \%)$ & $1(3,2 \%)$ \\
\hline
\end{tabular}

Kết quả OCT sau 6 tuần của nhóm nghiên cứu có $19 / 31$ bệnh nhân $(61,3 \%)$ không có bất thường gì, không có trường hợp nào có phù hoàng điểm dạng nang, có $6 / 31$ mắt $(19,4 \%)$ có DDVM tập trung, 4/31 mắt (12,9\%) có dịch dưới võng mạc nhiều nang nhỏ, 1 mắt $(3,2 \%)$ có màng trước võng mạc và 1 bệnh nhân có dấu hiệu đầu tiên của hội chứng co kéo dịch kính hoàng điểm (HCHD). 3 tháng sau phẫu thuật có 1 trường hợp dịch đã tiêu đi và xuất hiện thểm 1 trường hợp có MTVM vì thế số trường hợp có bất thường hình thái trên OCT là không đổi 12/31 mắt $(38,7 \%)$.

Trong nghiên cứu này chúng tôi không thấy có trường hợp nào có phù hoàng điểm dạng nang mặc dù phù hoàng điểm dạng nang được cho là một trong những bất thường vùng hoàng điểm thường hay gặp sau phẫu thuật bong võng mạc qua hoàng điểm. Có thể giải thích điều này bởi sự hoàn thiện về kỹ thuật cũng như những trang thiết bi phẫu thuật hiện đại và sự hỗ trợ của các thuốc chống viêm giúp hạn chế tình trạng phù hoàng điểm sau phẩu thuật.

Sau phẫu thuật có 1 trường hợp có hội chứng co kéo dịch kính hoàng điểm ở giai đoạn rất sớm phát hiện trên OCT ngay ở thời điểm 6 tuần sau phẫu thuật. Những tổn thương từ từ của lớp PT/PN và lớp MGN được phát hiện sau 3 tháng trong khi sau 6 tuần vấn chưa có tình trang này. Điều này cho thây rằng, chính $\mathrm{HCDH}$ có thể góp phần gây tổn thương các tế bào quang thụ và cũng là nguyên nhân gây thất bại về lâu dài của phẫu thuật điều trị BVM. ${ }^{4}$

Sau phẫu thuật 6 tuần có 1 bệnh nhân có màng trước VM. Sự xuất hiện màng trước VM ở bệnh nhân này là khá sớm và tiến triển rõ ràng hơn sau 3 tháng. Một bệnh nhân có màng trước VM sau 3 tháng mặc dù không thấy bất thường về hình thái trên OCT sau 6 tuân. Cả hai bệnh nhân này đều được điều trị bằng phương pháp đặt đai củng mạc. Lý giải nguyên nhân sự hình thành MTVM sau phẫu thuật BVM có thể bởi sau phẫu thuật đai độn củng mạc, dịch kính không được cắt sach như trong phẫu thuật $\mathrm{CDK}$, thêm vòa đó là tình trạng lanh đông củng mạc trong mổ gây tình trạng viểm và gây ra hiện tượng tăng sinh của các tế bào đệm, đại thực bào hay các tế bào xơ... Sự tăng sinh này chính là cơ sở hình thành của MTVM. Tuy nhiên cũng có thể ở những bệnh nhân này đã xuất hiện MTVM từ trước, nhưng không phát hiện được trước khi phẫu thuật do VM bong mà chỉ phát hiện ra sau khi phẫu thuật thành công, VM áp lại trên lâm sàng. Trong các nghiên cứu theo dõi với thời gian khá dài của các tác giả trên thế giới cho thấy sự xuất hiện MTVM là từ. Sự xuất hiện MTVM là một trong những nguyên nhân gây hiện tượng giảm chất lượng thị giác bao gồm giảm thị lực tương phản, nhìn méo hình và thay đổi màu sắc sau phấu thuâtt BVM.

3.2 Thị lực bệnh nhân theo bất thường hình thái trên OCT. 6 tuần sau phẫu thuật trong nhóm không có bất thường hình thái trên OCT có $9 / 19$ mắt $(47,3 \%)$ có $T L>20 / 50$ trong khi đó ở nhóm có bất thường chỉ có $1 / 12$ mắt $(8,3 \%)$ có TL >20/50.

Bảng 2. Phân chia thị lực của bệnh nhân giữa nhóm có bất thường và không có bất thường hình thái trên OCT sau 3 tháng

\begin{tabular}{|c|c|c|c|c|}
\hline Thị lực & $>20 / 50$ & $\begin{array}{c}20 / 200< \\
T L \leq \\
20 / 50\end{array}$ & $\begin{array}{c}\leq \\
20 / 200\end{array}$ & Tổng \\
\hline $\begin{array}{l}\text { Không } \\
\text { bất } \\
\text { thường }\end{array}$ & $\begin{array}{c}11 \\
51,9 \%\end{array}$ & $\begin{array}{c}7 \\
36,8 \%\end{array}$ & $\begin{array}{c}1 \\
5,3 \%\end{array}$ & $\begin{array}{c}19 \\
100 \%\end{array}$ \\
\hline $\begin{array}{l}\text { Có bất } \\
\text { thường }\end{array}$ & $\begin{array}{c}2 \\
16,7 \% \\
\end{array}$ & $\begin{array}{c}10 \\
83,3 \% \\
\end{array}$ & $\begin{array}{c}0 \\
0 \% \\
\end{array}$ & $\begin{array}{c}12 \\
100 \%\end{array}$ \\
\hline Tống & $3(41,9 \%$ & $17(54,8 \%$ & $1(3,2 \%$ & $31(100 \%$ \\
\hline p & \multicolumn{4}{|c|}{0,039} \\
\hline
\end{tabular}


Sau 3 tháng, trong nhóm không có bất thường hình thái trên OCT có $11 / 19$ mắt (51,9\%) có TL > 20/50 trong khi đó ở nhóm có bất thường chỉ có $2 / 12$ mắt $(16,7 \%)$ có $T L>20 / 50$.

Sau 6 tuần và 3 tháng thị lực của nhóm không có bất thường và nhóm có bất thường trên OCT có sự khác biệt rõ ràng có ý nghĩa thống kê với $p<0,05(p=0,021$ và $p=0,039)$. Theo đó nhóm có bất thường OCT trước mổ có thị lực thấp hơn nhóm không có bất thường.
Theo các nghiên cứu trước đây của các tác giả đã cho thấy những bất thường sau phẫu thuật BVM như sự xuất hiện màng trước võng mạc và tình trạng co kéo dịch kính hoàng điểm là một trong những nguyên nhân gây giảm thị lực của bệnh nhân sau mổ BVM và cũng là nguyên nhân gẩy ra sự thất bại của phẫu thuật điêu trị BVM. Cùng với đó sự tồn tại DDVM cũng là yếu tố được chứng minh có liển quan đến sự chậm hồi phục của thị lực ${ }^{5,6}$.

\subsection{Thị lực bệnh nhân theo sự tồn lưu DDVM trên OCT \\ Bảng 3. Phân chia thị lực của bệnh nhân theo sự tồn lưu DDVM trên OCT và thị lực của bệnh nhân sau 3 tháng}

\begin{tabular}{|c|c|c|c|c|c|c|c|c|}
\hline \multicolumn{5}{|c|}{ Sau 6 tuần } & \multicolumn{4}{|c|}{ Sau 3 tháng } \\
\hline $\begin{array}{l}\text { Thị lực } \\
\text { DDVM }\end{array}$ & $>20 / 50$ & $\begin{array}{l}<20 / 200 \\
\leq 20 / 50\end{array}$ & $20 / 200$ & Tông & $>20 / 50$ & $\begin{array}{l}<20 / 200 \\
\leq 20 / 50\end{array}$ & $\leq 20 / 200$ & Tông \\
\hline Không & $9(42,9 \%)$ & $10(47,6 \%)$ & $2(9,5 \%)$ & $21(100 \%)$ & $12(54,5 \%)$ & $9(40,9 \%)$ & $1(4,5 \%)$ & $22(100,0 \%)$ \\
\hline Có & $1(10,0 \%)$ & $9(90,0 \%)$ & $0(0 \%)$ & $10(100 \%)$ & $1(11,1 \%)$ & $8(88,9 \%)$ & $0(0 \%)$ & $9(100,0 \%)$ \\
\hline Tống & $10(32,3 \%$ & $19(61,3 \%)$ & $2(6,5 \%)$ & $31(100 \%)$ & $13(41,9 \%)$ & $17(54,8 \%)$ & $1(3,2 \%)$ & $31(100,0 \%)$ \\
\hline $\mathbf{p}$ & \multicolumn{4}{|c|}{0,049} & \multicolumn{4}{|c|}{0,021} \\
\hline
\end{tabular}

Sau phẫu thuât chỉ có 1 mắt ở nhóm có DDVM có $T L$ > 20/ 50 ở cả 2 thời điểm 6 tuần và 3 tháng. Trong khi đó ở 6 tuần có $9 / 21$ mắt $(42,9 \%)$ và $12 / 22$ mắt $(54,5 \%) 3$ tháng sau phẫu thuật có $T L>20 / 50$.

Có sự khác nhau có ý nghĩa thống kê giữa nhóm có dịch dưới võng mạc và nhóm không có về thị lực $(p<0,05)$. Như vậy nhóm có DDVM sau phấu thuật có thị lực thấp hơn nhóm không có dịch sau cùng thời gian theo dõi.

Tất cả các bệnh nhân có dịch dưới võng mạc đều có TL > 20/200 và $\leq$ 20/50

Chúng tôi không tìm ra sư khác biệt giữa các nhóm có chiều cao DDVM khác nhau với thị lực của bênh nhân.

Nhiều nghiên cứu đã chỉ rõ sự tồn tại DDVM sau mổ BVM là môtt trong những bất thường hay gặp nhất sau phẩu thuật điều trị BVM nhất là BVM qua hoàng điểm. So sánh thị lực giữa nhóm có DDVM và nhóm không có DDVM sau mổ chúng tôi thấy sự khác biệt có ý nghĩa thống kê $(p<0,05)$. Theo đó thị lực ở nhóm có dịch dưới võng mạc có thị lực thấp hơn so với nhóm không có DDVM. Điều này đã được khẳng định từ các nghiên cứu trước đây. ${ }^{5,6}$

Tuy nhiên trong các nghiên cứu này thời gian nghiên cứu khá dài cho tới khi DDVM tiêu hết và cho thấy thị lực cuối cùng của bệnh nhân không khác nhau giữa nhóm có DDVM và không có DDVM. Do hạn chế về thời gian, trong nghiên cứu này chúng tôi không có theo dõi dài cho đên khi DDVM hết vì thế chúng tôi không thể khẳng định được việc thị lực cuối cùng của bệnh nhân có khác nhau giữa các nhóm có DDVM và nhóm không có dịch.

Trong nghiên cứu này chúng tôi cũng không thấy có mối tương quan giữa chiều cao DDVM và thị lực của bệnh nhân. Kết quả này cũng trùng với kết quả của Seo và của Wolfensberger. ${ }^{7,8}$

\section{KẾT LUẬN}

Mặc dù sau điều trị bong VM qua hoàng điểm thành công làm áp lại VM trên lâm sàng và siêu âm nhưng trên hình ảnh OCT phát hiện nhiều bất thường vùng hoàng điểm. Những bất thường này có giá trị trong giải thích cũng như tiên lượng khả năng hồi phục TL của bệnh nhân. Việc phẫu thuật sớm sẽ hạn chế những bất thường hình thái trên OCT như tình trạng DDVM hay co kéo dịch kính võng mạc.

\section{TÀI LIÊU THAM KHẢO}

1. Schwartz SG, Flynn HW. Primary retinal detachment: scleral buckle or pars plana vitrectomy:Curropin Ophthalmol. 2006;17(3):245250. doi:10.1097/01.icu.0000193097.28798.fc

2. Hassan TS, Sarrafizadeh $R$, Ruby AJ, Garretson BR, Kuczynski B, Williams GA. The effect of duration of macular detachment on results after the scleral buckle repair of primary, macula-off retinal detachments. Ophthalmology. 2002; 109(1):146-152. doi:10.1016/ S0161-6420 (01) 00886-7

3. Ricker LJAG, Noordzij LJ, Goezinne F, et al. PERSISTENT SUBFOVEAL FLUID AND INCREASED PREOPERATIVE FOVEAL THICKNESS IMPAIR VISUAL OUTCOME AFTER MACULA-OFF RETINAL DETACHMENT REPAIR: Retina. 2011;31(8):15051512. doi:10.1097/IAE.0b013e31820a6910 
4. Abouzeid $\mathbf{H}$, Wolfensberger $\mathbf{T J}$. Macular recovery after retinal detachment. Acta Ophthalmol Scand. 2006; 84(5):597-605. doi:10.1111/j.16000420.2006.00676.X

5. Delolme MP, Dugas B, Nicot F, Muselier A, Bron AM, Creuzot-Garcher C. Anatomical and Functional Macular Changes After Rhegmatogenous Retinal Detachment With Macula Off. Am J Ophthalmol. 2012;153(1):128-136. doi:10.1016/ j.ajo.2011.06.010

6. Joe SG, Kim YJ, Chae JB, et al. Structura recovery of the detached macula after retinal detachment repair as assessed by optical coherence tomography. Korean J Ophthalmol KJO.
2013;27(3):178-185.

doi:10.3341/kjo.2013.27.3.178

7. Seo JH, Woo SJ, Park KH, Yu YS, Chung H. Influence of Persistent Submacular Fluid on Visual Outcome After Successful Scleral Buckle Surgery for Macula-off Retinal Detachment. Am J Ophthalmol. doi:10.1016/j.ajo.2008.01.005 2008;145(5):915-922.e1.

8. Wolfensberger TJ, Gonvers $\mathbf{M}$. Optical coherence tomography in the evaluation of incomplete visual acuity recovery after macula-off retinal detachments. Graefes Arch Clin Exp Ophthalmol. 2002;240 (2):85-89. doi:10.1007/ s00417-001-0410-6

\section{THUỐC UỐNG DÙNG CHO TRẺ EM}

\section{TÓM TẮT}

Việc nghiên cứu phát triển các công thức thuốc uống dùng cho trẻ em đang là vấn đề thách thức đối với các nhà nghiên cứu bào chế. Khó khăn lớn nhất đối với các dạng bào chế này là liều dùng tính theo cân nặng và phải hạn chế được mùi vị khó chịu. Hiện nay, các chế phẩm thuốc uống dùng cho trẻ em có thể là dạng bào chế có sẵn hoặc phải thao tác trước khi sử dụng. Các chế phẩm có thể dùng ngay bao gồm dung dịch uống, si rô, hốn dịch thuốc, viên nén, viên nén mini, viên nhai, viên nén phân tán trong miệng, màng phim hòa tan trong miệng. Các chế phẩm phải thao tác trước khi sử dung bao gồm bôt pha dung dịch hoặc hỗn dịch, viên phân tán tạo hốn dich, viên sủi bọt, viên nén mini hoăc viên nang chứa bột có thể trộn với đồ ăn hoăcc đồ uống. Bài báo này trình bày các dạng bào chế dùng đường uống cho trẻ em. Bài báo cũng đưa ra những tiến bộ mới trong việc phát triển các dạng bào chế dùng cho trẻ em và dụng cụ phân liều đường uống dùng cho trẻ em.

Tư khóa: thuốc, trẻ em, uống

\section{SUMMARY \\ PEDIATRIC ORAL FORMULATIONS}

Pediatric oral formulations can be quite scientifically challenging to develop. The prerequisites for both a measurable dosage form to administer based upon bodyweight, and also taste-masking are two of the challenges for pediatric oral formulations. Oral pediatric formulations are available in some different varieties and can be either a ready-to-use formulation or require manipulation. Ready-to-use formulations include oral solution, syrup, suspension, tablets, mini-tablets, chewable tablet, orally disintegrating tablet, oral soluble films. Formulations requiring manipulation include oral powder for

*Trường Đại hoc Dược Hà Nội

Chịu trách nnhiệm chính: Dướng Thị Hồng Ánh

Email: anhdth@hup.edu.vn

Ngày nhân bài: 5.01 .2021

Ngày phản biên khoa hoc: 5.3.2021

Ngày duyệt bài: 15.3.2021

\section{Dương Thị Hồng Ánh*}

constitution to a solution or suspension, tablet for constitution to a suspension, effervescent tablet, minitablet or powder in a capsule to mix with food or drink. In this article, the various types of formulations administered orally to pediatrics are presented. This paper also provides some recent progress in the development of pediatric formulations and delivery devices for pediatric oral administration.

\section{GIỚI THIÊU CHUNG}

Theo phân loại của Tổ chức $Y$ tế Thế giới (WHO), trẻ em được tính từ lúc mới sinh đến khi 18 tuổi, trong đó các nhóm tuổi cần có những lưu ý đặc biệt là: Sơ sinh (từ 0 đến 28 ngày tuổi), nhũ nhi (1-12 tháng tuổi) và trẻ em (1-12 tuổi). Trẻ em không phải là người lớn thu nhỏ vì có nhiều đặc điểm giải phẫu, sinh lý, tâm lý, bệnh lý... khác xa người lớn. Do đó, hấp thu, phân bố, chuyến hóa, thải trừ thuốc ở trẻ em có nhiều đặc điểm mà các nhà nghiên cứu bào chế phải lưu ý khi nghiên cứu xây dựng công thức thuốc dùng cho trẻ em.

Hiện nay, các dạng bào chế thuốc thường chỉ được thiết kế dành cho người lớn, không dành riêng cho trẻ em, gây khó khăn trong việc sử dụng. Điều này có thể dẫn đến việc khó xác định dược động học của các loại thuốc do chưa được nghiên cứu đầy đủ trên trẻ em hoặc lựa chọn thuốc không thích hợp cho trẻ em. Chính vì vậy, việc nghiên cứu các dạng bào chế thích hợp dùng cho trẻ em là vấn đề cấp thiết. Trong đó, đường uống là đường dùng phổ biến và thích hợp nhất cho trẻ em. Bài báo này trình bày tóm tắt một số dạng bào chế và hệ phân phối thuốc dùng qua đường uống cho trẻ em và một số hướng nghiên cứu về bào chế thuốc uống dùng cho trẻ em hiện nay.

\section{BÀO CHẾ THUốC UỐNG CHO TRẺ EM}

